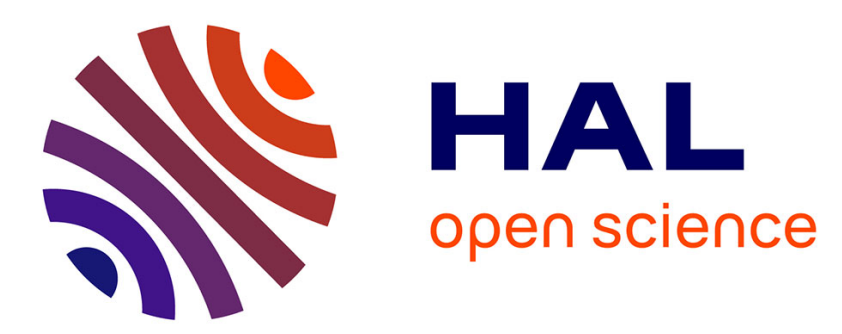

\title{
The Impact of Ge Grading on the Bias and Temperature Characteristics of SiGe HBT Precision Voltage References
}

\author{
M. Latham, J. Cressler, A. Joseph, R. Jaeger
}

\section{- To cite this version:}

M. Latham, J. Cressler, A. Joseph, R. Jaeger. The Impact of Ge Grading on the Bias and Temperature Characteristics of SiGe HBT Precision Voltage References. Journal de Physique IV Proceedings, 1996, 06 (C3), pp.C3-113-C3-118. 10.1051/jp4:1996317 . jpa-00254235

\section{HAL Id: jpa-00254235 https://hal.science/jpa-00254235}

Submitted on 1 Jan 1996

HAL is a multi-disciplinary open access archive for the deposit and dissemination of scientific research documents, whether they are published or not. The documents may come from teaching and research institutions in France or abroad, or from public or private research centers.
L'archive ouverte pluridisciplinaire HAL, est destinée au dépôt et à la diffusion de documents scientifiques de niveau recherche, publiés ou non, émanant des établissements d'enseignement et de recherche français ou étrangers, des laboratoires publics ou privés. 


\title{
The Impact of Ge Grading on the Bias and Temperature Characteristics of SiGe HBT Precision Voltage References
}

\author{
M.S. Latham, J.D. Cressler, A.J. Joseph and R.C. Jaeger \\ Alabama Microelectronics Science and Technology Center, Electrical Engineering Department, 200 Broun \\ Hall, Auburn University, Auburn, Alabama 36849, U.S.A.
}

\begin{abstract}
We analyze the effects that the Ge profile shape has upon the bias and temperature characteristics of SiGe HBT's. The widely used bandgap reference (BGR) design equation and a more general analytical expression we developed incorporating Ge grading are used to compare silicon devices to their SiGe counterparts. Measurement and simulation show that although the Ge-ramp effect is negligible in the -55 to $85^{\circ} \mathrm{C}$ range, it can become important as the temperature drops, perhaps affecting the operation of SiGe circuits in the $77 \mathrm{~K}$ regime.
\end{abstract}

\section{INTRODUCTION}

The past few years have seen significant progress in SiGe HBT technology. The SiGe HBT was first demonstrated in 1987 [1], and since then devices with $\mathrm{f}_{\mathrm{T}}$ and $\mathrm{f}_{\mathrm{MAX}}$ greater than 50 $\mathrm{GHz}$ have been used to realize such circuits as a $1.0 \mathrm{GS} / \mathrm{sec} 12$-bit $\mathrm{A} / \mathrm{D}$ converter [2], as well as mixers and voltage-controlled oscillators operating in the $5-25 \mathrm{GHz}$ range $[3,4]$. With performance figures such as these, there is great potential for the use of SiGe in low-cost, highspeed circuits for RF, microwave, and analog applications. The $a c$ and $d c$ characteristics of SiGe circuits at room temperature are significantly better than those of silicon [2], and both its gain and frequency response improve with cooling, thus making SiGe HBT's ideally suited for cryogenic applications [5].

To test the applicability of SiGe HBT technology to precision analog circuitry, however, its stability over temperature and bias must be proven. It has been shown that Ge grading across the base can have a negative impact upon collector current behavior, and hence current gain, in SiGe HBT's operating at low temperature [6]. Since its introduction by Wildar in 1971 [7], the bandgap reference (BGR) circuit has been widely used as a voltage reference source in A/D and $\mathrm{D} / \mathrm{A}$ converters, voltage regulators, and other precision analog circuits due to its good long-term stability and its ability to operate at low supply voltages. In this paper we experimentally examine 
the effects of Ge grading on the bias and temperature characteristics of SiGe HBT's for BGR applications.

\section{THE Ge-RAMP EFFECT}

We must first examine the effects of the Ge profile shape on the operation of the HBT in order to analyze the performance of precision SiGe circuits. The collector current at any bias of a graded-base SiGe HBT is exponentially dependent upon the amount of Ge at the edge of the emitter-base space-charge region. If we imagine increasing the collector current, the base-emitter voltage also increases and the space-charge region contracts, thereby reducing the amount of $\mathrm{Ge}$ seen by the device at that boundary (refer to Fig. 1). The dependence of the collector current on the Ge profile is given in equation (1):

$$
J_{C, S i G e}=\frac{q D_{n b}\left(e^{q V_{B E} / k T}-1\right) n_{i o}^{2} e^{\Delta E_{g b}^{a p p} / k T}}{N_{a b}^{-} W_{b}}\left[\frac{\widetilde{\gamma \eta} e^{\Delta E_{g, G e}(0) / k T} \Delta E_{g, G e}(\text { grade }) / k T}{1-e^{-\Delta E_{g, G e}(\text { grade) } / k T}}\right]
$$

where $E_{g, G e}(0)$ is the bandgap narrowing due to $\mathrm{Ge}$ at the emitter-base depletion edge at bias $V_{B E \text {, }}$ $\Delta E_{\text {g,Ge }}$ (grade) is the grading across the quasi-neutral base, $\tilde{\gamma}$ is the position-averaged density-ofstates reduction factor $\left(\left(N_{C} N_{V}\right)_{S i G e} /\left(N_{C} N_{V}\right)_{S i}\right)$, and $\widetilde{\eta}$ is the ratio of electron diffusivities in the base $\left(\left(\widetilde{D}_{n b}\right)_{s i G e} /\left(D_{n b}\right)_{S i}\right)$. The result is a degradation in $J_{C}$ (hence $\beta$ ) as we increase the baseemitter (BE) bias. In addition, because $J_{C}$ depends exponentially on the Ge-induced bandgap reduction at the $\mathrm{BE}$ junction divided by $k T$, this effect becomes more pronounced at cryogenic temperatures [6].

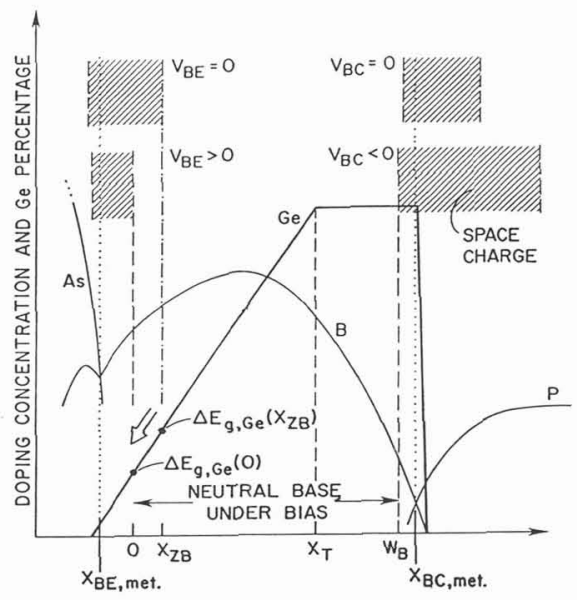

Fig. 1. The emitter-base space-charge region and the Ge ramp effect. 
To determine the effects of the Ge-induced ramp effect on the BGR circuit, we must recast the collector current equation into the familiar BGR design equation (2) [8]:

$$
V_{B E}=E_{g e}-\frac{T}{T_{R}}\left(E_{g e}-V_{B E R}-\frac{k T_{R}}{q} \ln \frac{I_{C}}{I_{C R}}+m \frac{k T_{R}}{q} \ln \frac{T}{T_{R}}\right)
$$

In equation (2), $E_{g e}$ is the average base bandgap voltage in the presence of doping and $T_{R}, I_{C R}$, and $V_{B E R}$ are the reference values of the respective parameters (typically referenced to $300 \mathrm{~K}$ ). First, the process-dependent parameters $(B)$ and the Ge profile terms $(z)$ can be lumped together as in equation (3),

$$
I_{C}=B T^{m} e^{-E_{g} / k T} e^{q V_{B E} / k T} z
$$

and rewritten in terms of the base-emitter voltage (equation (4) ). In practice, we can "measure"

$$
V_{B E}=E_{g}+\frac{k T}{q} \ln \frac{I_{C}}{z B T^{m}}
$$

the base-emitter voltage at a reference temperature and collector current and solve for the lumped process parameters $(B)$. Inserting the lumped parameters back into the original $V_{B E}$ equation and simplifying yields the desired result (equation (5)).

$$
V_{B E}=\left(E_{g e}-\Delta E_{g, G e}(0)\right)-\frac{T}{T_{R}}\left[\begin{array}{l}
\left(E_{g e}-\Delta E_{g, G e}(0)\right)-V_{B E R}-\frac{k T_{R}}{q} \ln \frac{I_{C}}{I_{C R}}+m \frac{k T_{R}}{q} \ln \frac{T}{T_{R}} \\
+\frac{k T_{R}}{q} \ln \frac{1-\exp \left(-\Delta E_{g, G e}(\text { grade })_{R} / k T_{R}\right.}{1-\exp \left(-\Delta E_{g, G e}(\text { grade }) / k T\right.}+\frac{k T_{R}}{q} \ln \frac{T_{R}}{T} \frac{\Delta E_{g, G e}(\text { grade })}{\Delta E_{g, G e}(\text { grade })_{R}}
\end{array}\right]
$$

The effects of $\mathrm{Ge}$ on the base-emitter voltage of the transistor can be gleaned directly from this more generalized result. Observe that the effective bandgap at the emitter-base junction is simply the silicon result with bandgap narrowing due to doping, $E_{g e}$, minus the bandgap reduction due to the amount of $\mathrm{Ge}$ at the junction, $\Delta E_{g_{0} G e}(0)$. In addition, the shape of $V_{B E}$ on temperature is changed due to the addition of $\mathrm{Ge}$, as is apparent in the last two terms of the equation. The ratio $T / T_{R}$ enhances this effect. For temperatures near the reference temperature, the last two terms in the equation have little effect on $V_{B E}\left(I_{C}, T\right)$, though as temperature decreases these effects can become more pronounced. This result will later be used to compare the measurements of $\mathrm{Si}$ and SiGe devices.

\section{RESULTS AND DISCUSSION}

The SiGe HBT's measured were fabricated using a self-aligned, deep- and shallow- trench isolated, polysilicon emitter technology (Fig. 2) [9]. The graded SiGe base was deposited using the UHV/CVD technique. Devices were wirebonded in 68-pin LCC packages and cooled in a 
cryostat system to ensure accurate thermometry. The base-emitter voltage at $I_{C}=10,50$, and 100 $\mu \mathrm{A}$ for bandgap core transistors $(\mathrm{A}=8)$ from two different SiGe HBT profiles (Fig. 3) and one $\mathrm{Si}$

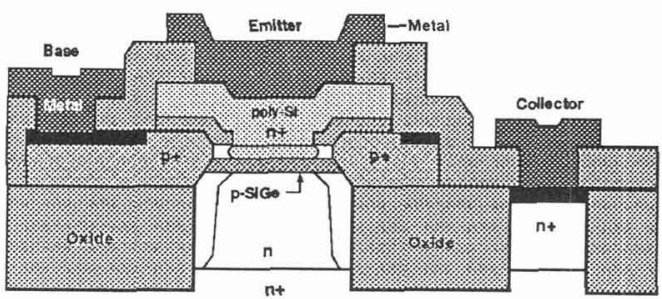

Fig. 2. Device cross-section of the SiGe HBT used in this study.

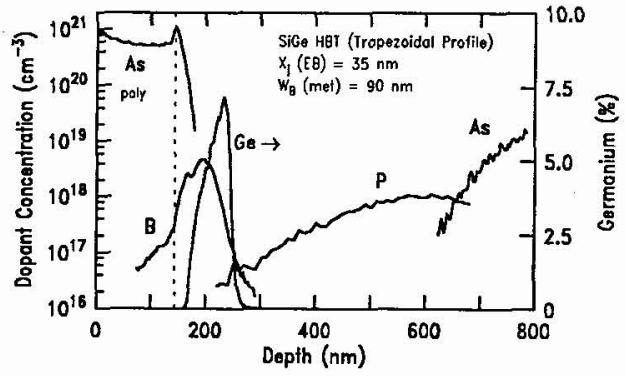

Fig. 3. SIMS data for a typical SiGe HBT.

BJT control were measured to six decimal place accuracy over a temperature range of -55 to 85 ${ }^{\circ} \mathrm{C}$. Gummel plots were measured at each temperature to ensure proper device operation. A representative Gummel plot for a $1.0 \times 2.5 \times 8 \mu \mathrm{m}^{2}$ device at $218 \mathrm{~K}$ and $358 \mathrm{~K}$ is shown in Fig. 4, and the collector currents across temperature of a typical SiGe HBT are shown in Fig. 5, with the three bias points indicated. The $V_{B E}$ data was collected by an HP 4155 using a time-sampled measurement and is shown in Fig. 6 for the three profiles at $10 \mu \mathrm{A}$ and $100 \mu \mathrm{A}$.

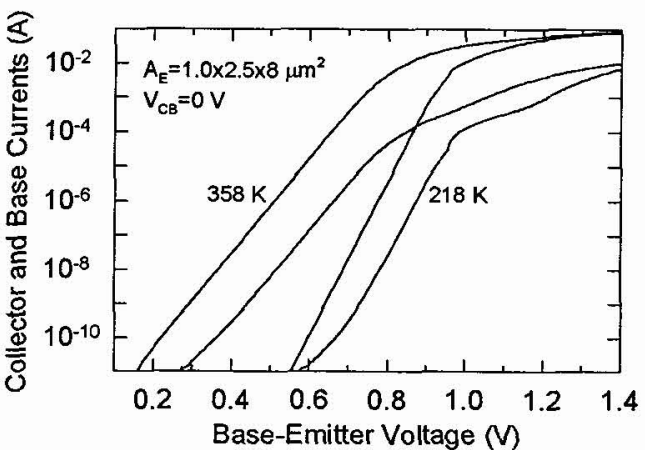

Fig. 4. Gummel plots at $358 \mathrm{~K}$ and $218 \mathrm{~K}$ for a $1.0 \times 2.5 \times 8 \mu \mathrm{m}^{2} \mathrm{SiGe} \mathrm{HBT}$.

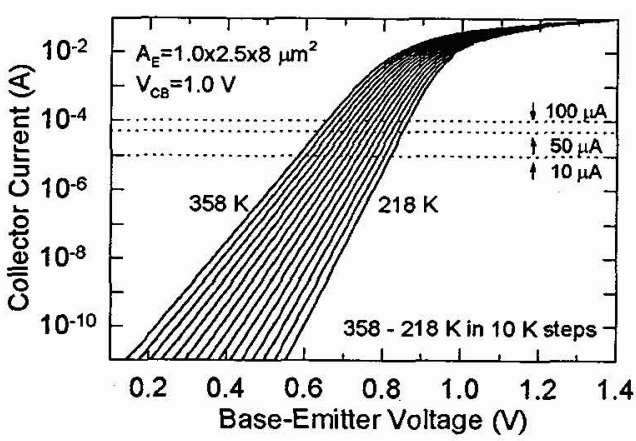

Fig. 5. Collector currents over temperature for a $1.0 \times 2.5 \times 8 \mu \mathrm{m}^{2} \mathrm{SiGe} \mathrm{HBT}$.

Because proper design of BGR circuits requires extremely accurate knowledge of $V_{B E}\left(J_{C}, T\right)$, we might naively expect them to be sensitive to the above-described Ge-ramp effect. One of our goals was to see if SPICE can accurately model $V_{B E}\left(I_{C}, T\right)$ in SiGe HBT's. To test this, we fit the BGR design equation (1) to the data to determine the values of $E_{g e}$ and $m$. In this 
analysis of equation (1), $E_{g e}$ is the average base bandgap in the presence of doping and Geinduced bandgap narrowing, and $T_{R}, I_{C R}$, and $V_{B E R}$ are the reference values of the respective parameters $\left(300 \mathrm{~K}, 50 \mu \mathrm{A}, V_{B E}\left(I_{C R}, T_{R}\right)\right)$. Of interest is the inferred value of the EG $\left(E_{g e}\right)$ SPICE parameter that controls the slope and intercept of $V_{B E}(T)$ (see Fig. 6$)$ and the XTI ( $m$, saturation current temperature exponent) parameter that controls the deviation of $V_{B E}(T)$ from linearity (Fig. 7). The values of $E_{g e}$ determined from this experiment appear in Fig. 6, where the value of this parameter for both the Ge profiles is lower than that of the $\mathrm{Si} \mathrm{BJT}$, as expected. The deviation from linearity is determined by drawing a line between the $V_{B E}$ 's at the temperature extremes and then subtracting this line from the actual $V_{B E}$ data. The values of $m$ and the deviation from linearity that result are also shown in Fig. 7.

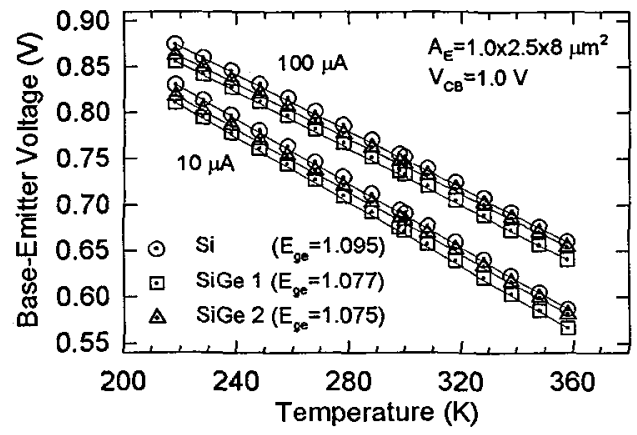

Fig. 6. Base-emitter voltages over temperature for $\mathrm{Si}$ and $\mathrm{SiGe}$ devices with emitter areas of $1.0 \times 2.5 \times 8 \mathrm{~m}^{2}$.

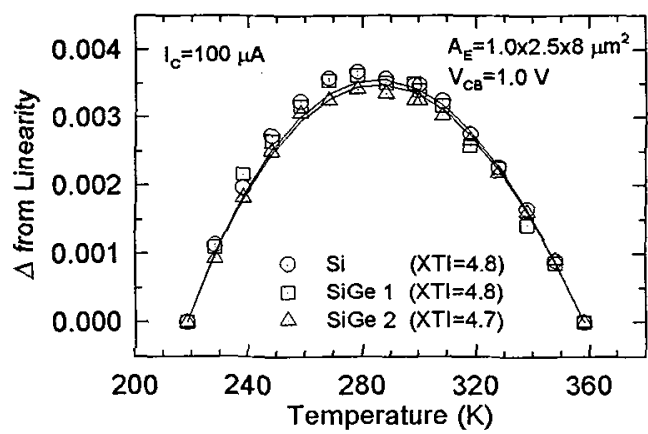

Fig. 7. Deviation from linearity for Si and SiGe $\mathrm{V}_{\mathrm{BE}}$ data of Fig. 6.

The matching BGR core transistor whose area is $1.0 \times 2.5 \mu^{2}$ was also measured in this investigation, although the results are not shown. Since the area of this device is 8 times smaller than the other core transistor, the $V_{B E}$ as in Fig. 6 is naturally higher. However, the shape of $V_{B E}$ over $T$ was identical for the range of temperatures measured, a result which bodes well for the operation of BGR circuits between -55 to $85^{\circ} \mathrm{C}$. However, it is unclear what happens to the shape of this curve when the temperature is lowered to $77 \mathrm{~K}$. It is evident that over the -55 to 85 ${ }^{\circ} \mathrm{C}$ temperature range there is no significant difference between the $\mathrm{Si}$ and $\mathrm{SiGe}$ devices in the shape of the $V_{B E}$ curve, though the effective bandgap is naturally reduced by the addition of Ge to the base.

We performed SCORPIO simulations [10] using calibrated profiles as well as a hypothetical Ge profile of larger grading to further test these conclusions down to $77 \mathrm{~K}$. Fig. 8 corroborates our measurements in that there is little difference in the shape of VBE on $T$ for the three different profiles in the -55 to $85^{\circ} \mathrm{C}$ temperature range. However, once the simulation range was extended down to $77 \mathrm{~K}$, it can be seen in Fig. 9 that the difference between the three profiles becomes significant. Therefore, the operation of SiGe precision analog circuits below the -55 to $85^{\circ} \mathrm{C}$ temperature range, especially near $77 \mathrm{~K}$, is expected to be affected by these Ge ramp effects. 


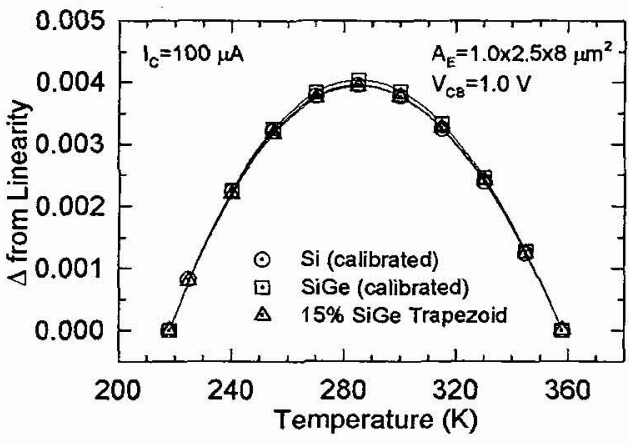

Fig. 8. SCORPIO simulation results showing deviation from linearity for calibrated and hypothetical profiles between 218 and $358 \mathrm{~K}$.

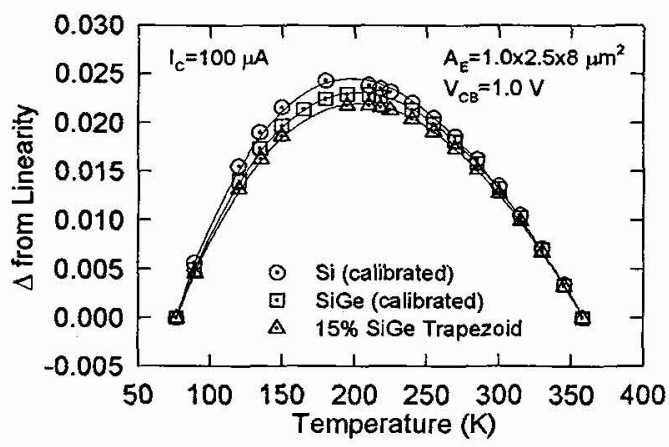

Fig. 9. SCORPIO simulation results showing deviation from linearity for calibrated and hypothetical profiles down to $77 \mathrm{~K}$.

\section{CONCLUSION}

This analysis of the temperature and bias dependence of the base-emitter voltage of SiGe HBT's is key to assessing the operation of this technology in precision analog circuits. It does not appear that the Ge grading in the base of these HBT's will have a detrimental effect on the operation of BGR circuits over the temperature range of -55 to $85^{\circ} \mathrm{C}$, though these effects do become more pronounced with cooling. More investigation into the operation of BGR circuits using SiGe HBT's is needed, as well as experimental results in the $77 \mathrm{~K}$ range, and these are presently underway.

Acknowledgments - The authors would like to thank B. Gilbert, P. Brokaw, D. Buss, and T. Tewksbury of Analog Devices and C. Ellis of Auburn University for their contributions to this work, and IBM Microelectronics for wafer fabrication. We are also grateful to the SiGe research group at Auburn: W. Ansley, D. Richey, S. Jayanarayanan, S. Mathew, J. Roldan, and G. Bradford. This work was supported by a National Science Foundation Graduate Research Fellowship and the Office of Naval Research under grant \# N00014-94-0690.

\section{References}

[1] S. S. Iyer et al., IEDM Tech. Dig. (1987) 874-876.

[2] D. L. Harame et al., IEDM Tech. Dig. (1993) 71-74.

[3] L. Larson et al., IEEE Int. Solid-State Circuits Conf. (1996) 80-81.

[4] J. R. Long et al., IEEE Int. Solid-State Circuits Conf. (1996) 82-83.

[5] J. D. Cressler, J. de Physique IV 4 (1994) 101-110.

[6] E. F. Crabbé et al., IEEE Electron Device Lett. 14 (1993) 193-195.

[7] R. J. Wildar, IEEE J. Solid-State Circuits 6 (1971) 2-7.

[8] A. P. Brokaw, IEEE J. Solid-State Circuits 9 (1974) 388-393.

[9] D. L. Harame et al., IEEE Trans. on Electron Devices 42 (1995) 469-482.

[10] D. M. Richey et al., J. de Physique IV 4 (1994) 127-132. 